\title{
$\mathrm{NF}_{3}$ 添加有機金属気相堆積法による $\mathrm{ZnSe}$ 薄膜の作製
}

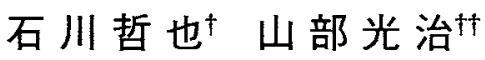 \\ 原 義徳 ${ }^{\dagger}$ 野田泰稔
}

東北大学工学部材料物性学科

J. Japan Inst. Metals, Vol. 60, No. 10 (1996), pp. 988-992

\section{Preparation of ZnSe Thin Films by Metalorganic Chemical Vapor Deposition Using $\mathrm{NF}_{3}$}

Tetsuya Ishikawa, Mitsuharu Yamabe,

Yoshinori Hara and Yasutoshi Noda

Department of Materials Science, Faculty of Engineering, Tohoku University, Sendai

\begin{abstract}
The growth of $\mathrm{ZnSe}$ films was performed at $672 \sim 723 \mathrm{~K}$ by metalorganic chemical vapor deposition using an atmospheric-pressure, $\mathrm{rf}$-heated and horizontal reactor. Diethylzinc (DEZn) and diethylselenide (DESe) as source materials were fed by $\mathrm{H}_{2}$ gas with the $[\mathrm{VI}] /[\mathrm{II}]$ ratio on a semi-insulation $\mathrm{GaAs}(100)$ substrate. Nitrogen trifluoride $\left(\mathrm{NF}_{3}\right)$ was used as co-reactant. The growth rate estimated by the profile meter indicates that $\mathrm{NF}_{3}$ drastically enhanced the growth rate at the flux $\left(f_{\mathrm{NF}_{3}}\right)$ of about $0.3 \mu \mathrm{mol} / \mathrm{s}$. The increased growth rate might be due to some chain reaction of dealkylation from $\mathrm{DESe}$ with $\mathrm{NF}_{3}$. Photoluminescence of the $\mathrm{ZnSe}$ films was measured at $77 \mathrm{~K}$ by using a He-Cd laser for excitation. For all the films grown at $f_{\mathrm{NF}_{3}}<0.3 \mu \mathrm{mol} / \mathrm{s}$, the donor-acceptor(D-A) pair emission was observed in the spectra, which corresponds to that reported on the nitrogen-doped p-type $Z n S e$. The result indicates that the nitrogen atoms from $\mathrm{NF}_{3}$ might be incorporated into the grown films. At $f_{\mathrm{NF}_{3}}>0.3 \mu \mathrm{mol} / \mathrm{s}$, the emission peak broadened in the region of $2.4-2.6 \mathrm{eV}$.
\end{abstract}

(Received May 7, 1996)

Keywords: metalorganic chemical vapor deposition, zinc selenide, co-reactant, nitrogen trifluoride, growth rate, photoluminescence, donor-acceptor pair emission

\section{I．緒言}

II-V族化合物半導体セレン化亜鉛 $(\mathrm{ZnSe})$ は，直接遷移型 のバンド構造を有し，そのバンドギャップ $\left(E_{\mathrm{g}}\right)$ は室温にお いて約 $2.7 \mathrm{eV}$ であり，波長 $460 \mathrm{~nm}$ の青色光の領域にある. そのため $\mathrm{ZnSe}$ は, 青色発光ダイオードや半導体青色レーザ 一等の青色発光半導体デバイス用材料として研究されてきた. 1991年に Haase ら(1)により世界で初めて ZnSeを用いた量 子井戸レーザーダイオードの作製が成功し，それ以降 $\mathrm{ZnSe}$ を基本とするデバイス作成の成功が相次いで報告されてい る(2)-(4)。これらの多くは，プラズマ支援分子線エピタキシ (MBE)による成長温度の低下, および, ラジカル化した原 子状窒素の添加による $\mathrm{p}$ 型伝導薄膜作製の成功などである. 今後さらに笑用化のためには有機金属気相堆積法(MOCVD) など，各種のプロセスによる $\mathrm{p}$ 型薄膜作製の研究が重要と なる・

$\dagger$ 東北大学大学院生

什東北大学大学院生, 現在 : (10東芝 生産技術研究所
MOCVDによるZnSe 薄膜作製の問題点は，原料である 有機金属ガス, なかでも，セレン原料がスにある(5)。初期に 用いられたセレン化水素 $\left(\mathrm{H}_{2} \mathrm{Se}\right)^{(6)}$ 㤋分解温度が室温近傍之 低いため，薄膜の成長の制御が困難であり，また，その分解 により生じた多量の水素が膜中に取り込まれて格子久陷の原 因となる.一方，有機セレンを使用した場合，多くは分解温 度 $723 \mathrm{~K}$ 以上の高温を必要とし，自己補償の原因となる欠 陥の生成や基板からの不純物の昖散等により薄膜の品質低下 につながる，とされてきた。

MOCVDに扣ける有機金属の熱分解においては，分解の 際に生じたラジカルが分解反応を促進することが知られてい る(7)。このような点を考慮して, 有機セレンの分解を促進 し, 成長速度を高めるため, 三フッ化窒素 $\left(\mathrm{NF}_{3}\right)$ などラジカ ル発生剂の添加が試みられている(8)。また， $\mathrm{NF}_{3}$ 添加では, その成分に窒素原子を含をことから，反応時炕窒素ラジカル が発生し，成長膜中に取り込まれてアクセプタとなることが 期待されるので, $\mathrm{p}$ 型 $\mathrm{ZnSe}$ 薄膜作製に有効な手段となると 考光られる。

本研究では，常圧に抏いて MOCVDに拈いて $\mathrm{NF}_{3}$ 添加し 
て ZnSe 薄膜の作製を行った. 得られた薄膜について成長条 件々成長速度の関係を求めるととるに，フォトルミネッセン ス $(\mathrm{PL})$ 測定に上る評価を行い, 窒素ドーピングの可能性を 検討した.

\section{II. 実験}

本実験で使用した MOCVD装置の概略図をFig. 1 亿示 す. 成長室火は, グラフォイトのサセプターを取り付け, 高 周波誘導加熱発振器( トーキン製 RF-14K) により加熱し た. 原料の有機金属ガスにはジェチル亜鉛 (DEZn), ジェチ ルセレン(DESe)（共にトリケミカル研究所侏製公称純度 99.999\%)を用いた.これらの原料ガスを搬送ガスの水素に より成長室へ導入した，Table 1 飞 $\mathrm{ZnSe}$ 薄膜の成長条件を 示す.

$\mathrm{GaAs}(100)$ 基板はアセトン中での超音波洗浄により脱脂 し，メタノールで置換した後イオン交換水で洗浄した．これ をエッチング液 $\left(\mathrm{H}_{2} \mathrm{SO}_{4}: \mathrm{H}_{2} \mathrm{O}_{2}: \mathrm{H}_{2} \mathrm{O}=5: 1: 1\right)$ 火より室温 で $2 \mathrm{~min}$ 間エッチングし，イオン交換水で置換して洗浄し た。これを乾燥後，サセプターに取り付けて，成長室内泊 入した，その後，成長室内を真空に引き，窒素々高純度水素 で数回置換したのち, 高純度水素を 1 気圧で成長時の流量 に設定した。成長開始前に基板はこの水素気流中で $853 \mathrm{~K}$ に特いて $300 \mathrm{~s}$ 間加熱した後，成長温度に保持した，成長温 度へ移行の際には成長室にDESeを流した。 $\mathrm{NF}_{3}$ 添加 MOCVDに打いては, $\mathrm{NF}_{3}$ (流束, $f_{\mathrm{NF}_{3}}$ ) む同時に流し， $\operatorname{DEZn}\left(f_{\mathrm{DEZn}}\right)$ ル対する DESe $\left(f_{\mathrm{DESe}}\right)$ の流束の割合 $([\mathrm{V}] /[\mathrm{II}]$

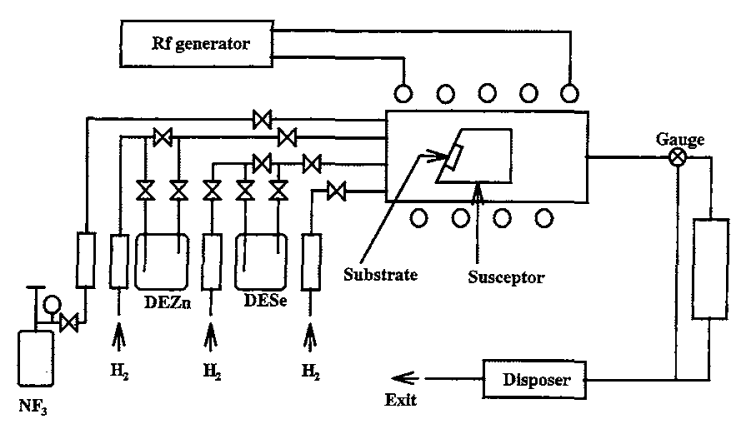

Fig. 1 Schematic diagram of the MOCVD apparatus.

Table 1 Growth conditions of $\mathrm{ZnSe}$ films.

\begin{tabular}{l|l}
\hline \hline Growth temperature $\left(T_{\text {growth }}\right)$ & $648 \sim 748 \mathrm{~K}$ \\
Growth pressure & $1 \mathrm{~atm}$ \\
Carrier gas & $\mathrm{H}_{2}$ \\
Total flow rate $\left(\mathrm{f}_{\text {total }}\right)$ & $1.67 \times 10^{-5} \mathrm{~m}^{3} / \mathrm{s}$ \\
Source gas fluxes & $\mathrm{f}_{\mathrm{DEZn}} ; 1.67 \times 10^{-7} \mathrm{~mol} / \mathrm{s}$ \\
& $\mathrm{f}_{\mathrm{DES}} ; 1.67 \times 10^{-7} \mathrm{~mol} / \mathrm{s} \times(1 \sim 3)$ \\
{$[\mathrm{VI}] /[\mathrm{II}]$} & $1 \sim 3$ \\
$\mathrm{NF}_{3}$ flux $\left(\mathrm{f}_{\mathrm{NF}}\right)\left(\mathrm{Ar}+1 \% \mathrm{NF}_{3}\right)$ & 0 or $1.67 \sim 6.67 \times 10^{-7} \mathrm{~mol} / \mathrm{s}$ \\
Substrate & Semi-insulating GaAs $(100)$ \\
Growth period & $1 \mathrm{~h}$ \\
Film thickness & $1 \sim 5 \mu \mathrm{m}$ \\
\hline
\end{tabular}

比を 1 抢よび 2 とした。成長は DEZn の導入により開始し， $3.6 \times 10^{3} \mathrm{~s}$ 後の停止に上り終了した. 冷却時, $473 \mathrm{~K}$ K括い て DESe を停止し，室温に打いて我素を停止した。

作製した薄膜の厚さは表面形状測定装置(Dektak 3030)に より湘定した.フォトルミネッセンス測定は励起光源として $\mathrm{He}-\mathrm{Cd} レ$ レ゙ー(波長 $325 \mathrm{~nm}, 13 \mathrm{~mW}$ )を, 分光器には焦点 距離 $1 \mathrm{~m}$ のダブルモノクロメーター(JASCO, CT1000D)を 用い，液体窒素温度 $(77 \mathrm{~K})$ 亿扣いて測定を行った。表面の 形態は走查電子顕微鏡 (SEM) Kより観察した。

\section{III. 結果と議論}

\section{1. 成長速度}

測定した薄膜の厚さから成長速度を見積り成長条件との関 係を求めた. Fig. 2 亿成長速度と成長温度の逆数との関係 を示す，成長温度が上昇するに伴って成長速度が上昇してい ることがわかる. 図中の破線はこれまで報告された活性化 エネルギーは $86.1 \mathrm{~kJ} / \mathrm{mol} \cdot \mathrm{K}^{(9)}$ 亿対応する関係を示す。 DMSe や DESe を原料ガスとするZnSe の MOCVD は原料 ガスの分解と薄膜の品質を考虑すると，通常 $723 \mathrm{~K}$ 以上が 適当されている.本研究では主として $723 \mathrm{~K}$ に打いて成長 を行ったが，予備実験で行った $723 \mathrm{~K}$ 以下での成長では，

成長速度が破線で示寸関倸から低下する傾向にあることが知 られた。

有機金属の分解と $\mathrm{ZnSe}$ の形成は以下の (1)-(4)の反応 で表される。

$$
\begin{aligned}
& \mathrm{DEZn}=\mathrm{Zn}+2 \mathrm{C}_{2} \mathrm{H}_{5}^{*}, \\
& \mathrm{DESe}+\mathrm{H}_{2}=\mathrm{H}_{2} \mathrm{Se}+2 \mathrm{C}_{2} \mathrm{H}_{5}^{*}, \\
& \mathrm{Zn}+\mathrm{H}_{2} \mathrm{Se}=\mathrm{ZnSe}_{\mathrm{n}}+\mathrm{H}_{2}, \\
& 2 \mathrm{C}_{2} \mathrm{H}_{5}^{*}+\mathrm{H}_{2}=2 \mathrm{C}_{2} \mathrm{H}_{6} .
\end{aligned}
$$

ここで，原料ガスは反応式(1)拉よび (2)に括ける分解の 際にアルキル基 $\left(\mathrm{C}_{2} \mathrm{H}_{5}^{*}\right)$ を生成し，これらが原料有機金属の

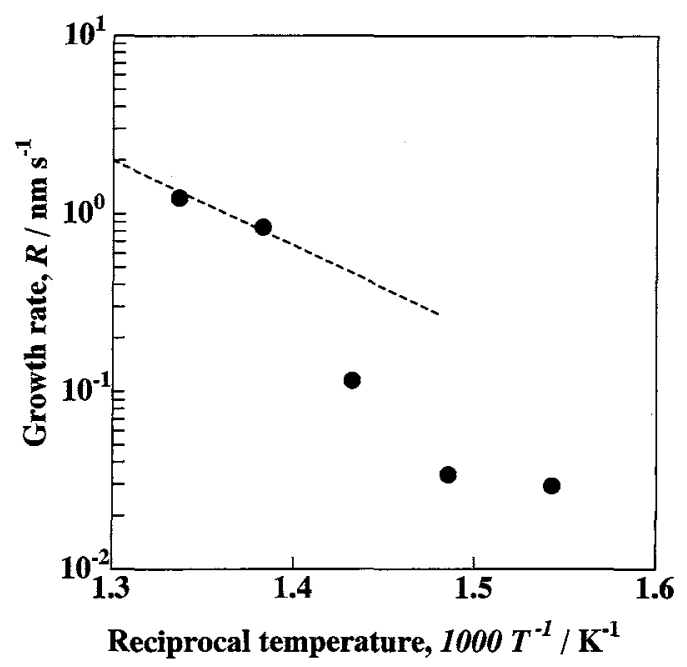

Fig. 2 Plots of growth rate vs. reciprocal temperature ([VI]/ $[\mathrm{II}]=2$ ). The dashed line corresponds to the literature data of the activation energy of $86.1 \mathrm{~kJ} / \mathrm{mol} \mathrm{K}^{(9)}$. 
分解を促進すると考光られている(7). 成長に打ける活性化過 程はDESe の分解過程である反応式 (2) と考光られている. Fig. 3 亿成長速度と $[\mathrm{V}] /[\pi]$ 比の関係を示す．［V] / [ II] $=2$ 付近までは成長速度は $[\mathrm{V}] /[\Pi]$ 比の増加に伴い増大寸 る傾向が認められた。度(1)-(4)に拈いて，ZnSeは DEZn 扣よびDESeの分解後に形成され，DESe の分解が DEZnにくらべて遅れることから，[N]/[II]比が2以下で は Seの量が少く反忘が原料がスの供給律速となる。そのた め, [U] $] /[\Pi]$ 比の増大とともに成長速度が増加する.

\section{2. ラジカル支援 MOCVD}

Fig. 4 飞 $673 \mathrm{~K}$ に扣㚈る成長速度と $\mathrm{NF}_{3}$ の添加量の関俰 を， [V] $] /[\Pi]$ 比が 1 牤よび 2 の場合について示寸。 [ V ] / $[I I]=1$ の場合, $f_{\mathrm{NF}_{3}}=3.0 \times 10^{-7} \mathrm{~mol} / \mathrm{s}$ 以下Kおいて, 添加 に伴う成長速度の変化はわずかであるが， $3.0 \times 10^{-7} \mathrm{~mol} / \mathrm{s}$ において成長速度は急激に増大し，その後は $f_{\mathrm{NF}_{3}}$ が増大して もほとんど変化しない． $\mathrm{NF}_{3}$ 添加に打けるDESeの分解反 応は次式 (5)-(7)で表されると考光られている(8).

$\left(\mathrm{C}_{2} \mathrm{H}_{5}\right)_{2} \mathrm{Se}+\mathrm{NF}_{3}=\mathrm{C}_{2} \mathrm{H}_{5} \mathrm{~F}+\mathrm{C}_{2} \mathrm{H}_{5} \mathrm{Se}^{*}+\mathrm{NF}_{2}^{*}$,

$\mathrm{C}_{2} \mathrm{H}_{5} \mathrm{Se}^{*}+\mathrm{NF}_{2}^{*}=\mathrm{C}_{2} \mathrm{H}_{5} \mathrm{~F}+\mathrm{Se}+\mathrm{NF}^{* *}$,

$\left(\mathrm{C}_{2} \mathrm{H}_{5}\right)_{2} \mathrm{Se}+\mathrm{NF}^{* *}=\mathrm{C}_{2} \mathrm{H}_{5} \mathrm{~F}+\mathrm{C}_{2} \mathrm{H}_{5} \mathrm{Se}^{*}+\mathrm{N}$.

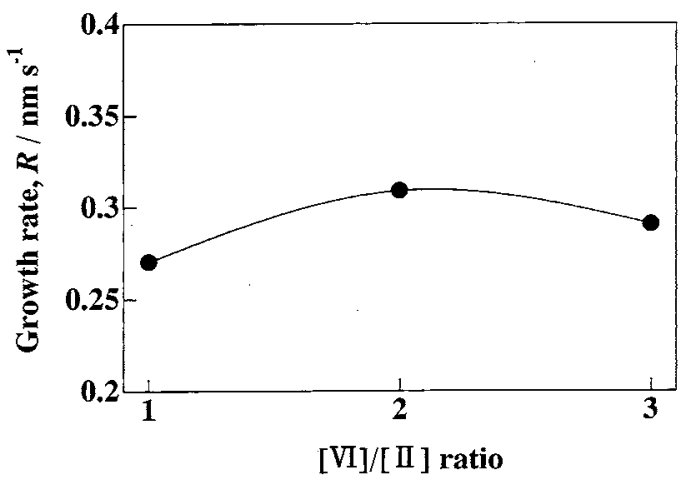

Fig. 3 Plots of growth rate vs. $[\mathrm{VI}] /[\mathrm{II}]$ ratio $\left(T_{\text {growth }}=723\right.$ $\mathrm{K})$.

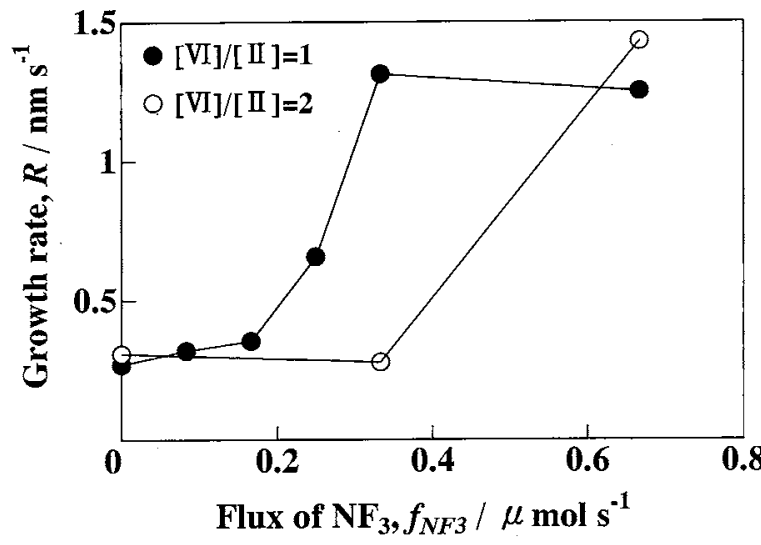

Fig. 4 Plots of growth rate vs. flux of $\mathrm{NF}_{3}\left(T_{\mathrm{growth}}=723 \mathrm{~K}\right)$.
ここで $\mathrm{NF}_{3}$ が成長速度に文ぼす影響について， $f_{\mathrm{NF}_{3}}$ が小さ い領域では原料ガス特に DESeの分解はあまり促進されず， また分解と成長は基板上で起こり，成長速度に与兄る影響は 小さいと考えられる。 さらに $f_{\mathrm{NF}_{3}}$ が増大すると原料ガスの分 解が（5)-(7)の反応により連鎖的に進行し，成長速度が急 激に増加する。 その後成長速度がほぼ一定になるのは，急激 な反応が基板表面以外の成長管内壁に特いてもおこり，基板 上への堆積は増加しないためと思われる。このよらに考える と, $\mathrm{NF}_{3}$ 添加により DESe の分解後の成長機構に変化が生 しててる可能性を示唆される.

3. フォトルミネッセンススペクトル

Fig. 5 は $\mathrm{NF}_{3}$ 無添加の場合の $\mathrm{PL}$ スペクトルと成長温度 との関係を示す。 $673 \mathrm{~K}$ 以下打ける成長では, $2.0 \mathrm{eV}$ 近 傍にピークをるつ幅の広い発光が支配的であり，このピーク エネルギーは，成長温度が上昇するに伴って高エネルギー側 に移行した. $698 \mathrm{~K}$ に执いて成長した薄膜では $2.7 \mathrm{eV}$ 近傍 にも発光ピークがみられた. $723 \mathrm{~K}$ 以上での成長した薄膜で は, $2.8 \mathrm{eV}$ 近傍の鋭いピークが支配的であった。これらの 発光の起源は文献から (10)-(12)，それぞれ，基板から拡散した Gaによるドナーに束縛された励起子 $\left(I_{2}, 2.788 \mathrm{eV}\right)$, ドナー ・アクセプター対(D-A, $2.692 \mathrm{eV}), \mathrm{Zn}$ 扣よび Se の空孔に よる SA (Self Activated, 〜2.0 eV) 発光と同定された。

従来バンド端近傍の発光，特に励起子発光のエネルギーは 膜厚に依存することが報告されて括り ${ }^{(13)}$ ，膜厚 $2 \sim 22 \mu \mathrm{m}$ の $\mathrm{ZnSe}$ 薄膜において，4.2 Kに打方自由励起子による発 光のエネルギーは2.8000 2.8007 eV の範囲で変化し，一 方バルク結晶では $2.802 \mathrm{eV}$ とされてい。本研究における $I_{2}$ 発光の起源については, $77 \mathrm{~K}$ のほか $4.2 \mathrm{~K} に$ 拀いても $\mathrm{PL}$

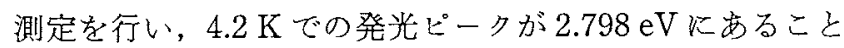

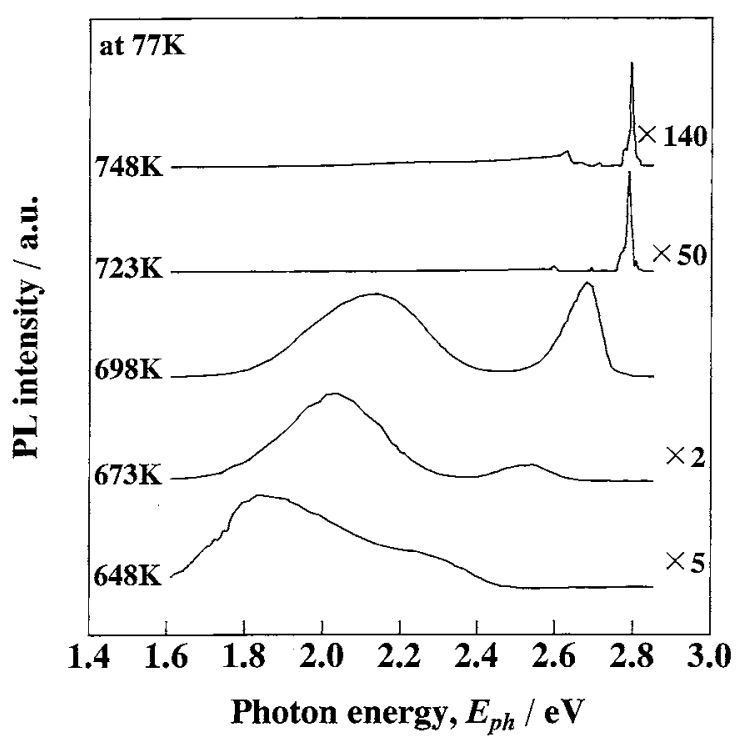

Fig. 5 Photoluminescence spectra of $\mathrm{ZnSe}$ films in terms of growth temperature $([\mathrm{VI}] /[\mathrm{II}]=2)$. 


\section{より同定した.}

これらの結果から，723 K 以上の高温で成長させた薄膜は 膜厚が大さく，非発光性再結合中心の少なく発光性再結合遷 移過程の寄与が大きい高品質の結晶であることが判明した． これは，DMSeやDESeを原料ガスとするZnSeの MOCVDによる高品質薄膜の作成には $723 \mathrm{~K}$ 以上での成長 が不可欠とする従来の報告と対応する結果である. $723 \mathrm{~K}$ 以 下の低温に补る成長により非発光性再結合中心が生ずる理 由は，分解生成物の基板表面上での应散が十分ではないため 2 次元成長が困難となり，膜中に格子欠陷が導入されるため と考光られる。

Fig. 6 に $f_{\mathrm{NF}_{3}}$ と $\mathrm{PL}$ スペクルの関係を示す。図には比 較のため無添加の場合のスペクトルを合わせて示す。 $f_{\mathrm{NF}_{3}}$ $=3.0 \times 10^{-7} \mathrm{~mol} / \mathrm{s}$ 以下K扣いて作製した試料は $2.70 \mathrm{eV}$ 近 傍にピークをるつD-A 対発光が支配的であった. $f_{\mathrm{NF}_{3}}$ がさ らに増大すると，この D-A ピークが消失し， $2.58 \mathrm{eV}$ にあ ったピークが強度を増しながら低エネルギー侧に移行した。

このピークは $\mathrm{Y}$ バンドと称好られ，結晶中の転位が起源之 されている(14).さらに，2.0 eV 近傍に観測される $\mathrm{SA}$ 発光 は, $f_{\mathrm{NF}_{3}}$ の増大に伴ってピーク強度が徐々に増加した。この 結果は， $f_{\mathrm{NF}_{3}}$ が $3.0 \times 10^{-7} \mathrm{~mol} / \mathrm{s}$ を越えると，急激な成長の 増大に伴い $\mathrm{Y}$ バンドやSA発光の起源となる欠陷が増大す ることを示している。

$\mathrm{NF}_{3}$ 添加に拈いては，(5)-(7)の反応式に扣いて成長時 に原子状窒素の発生が考克られ，結晶中に取り込まれてアク セプターとなる可能性がある. $77 \mathrm{~K}$ に和ける D-A 対発光エ ネルギ一は, $f_{\mathrm{NF}_{3}}=0.3-0.8 \times 10^{-7} \mathrm{~mol} / \mathrm{s}$ に扰いて $2.697 \mathrm{eV}$ であり，無添加の場合に比較して $5 \mathrm{meV}$ 高エネルギー側に 位置している.さらK $f_{\mathrm{NF}_{3}}=1.7 \times 10^{-7} \mathrm{~mol} / \mathrm{s}$ では発光のピ

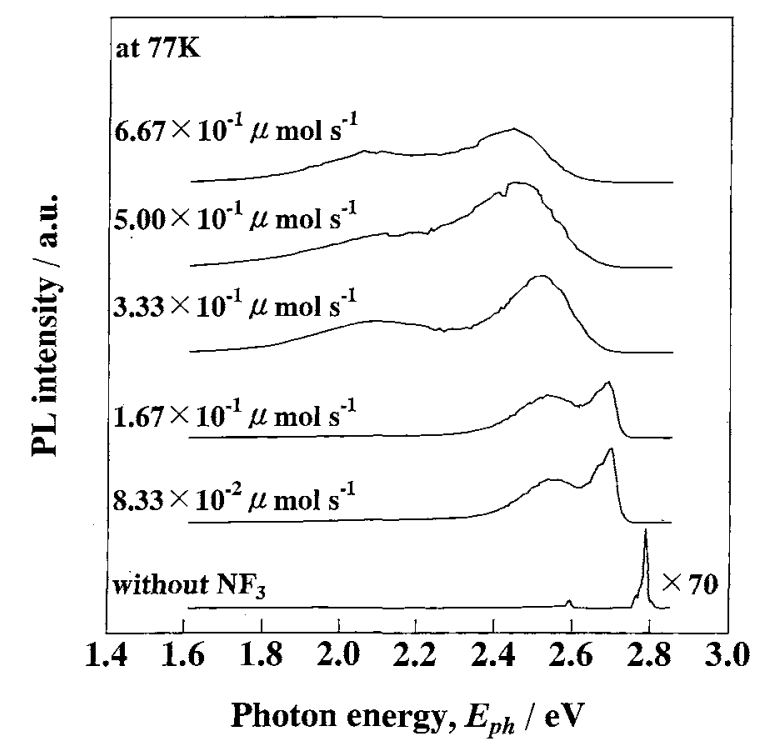

Fig. 6 Photoluminescence spectra of $\mathrm{ZnSe}$ films grown using $\mathrm{NF}_{3}$ at $T_{\text {growth }}=723 \mathrm{~K}$. Flux of $\mathrm{NF}_{3}$ is indicated in the figure $([\mathrm{VI}] /[\mathrm{II}]=1)$. (a)

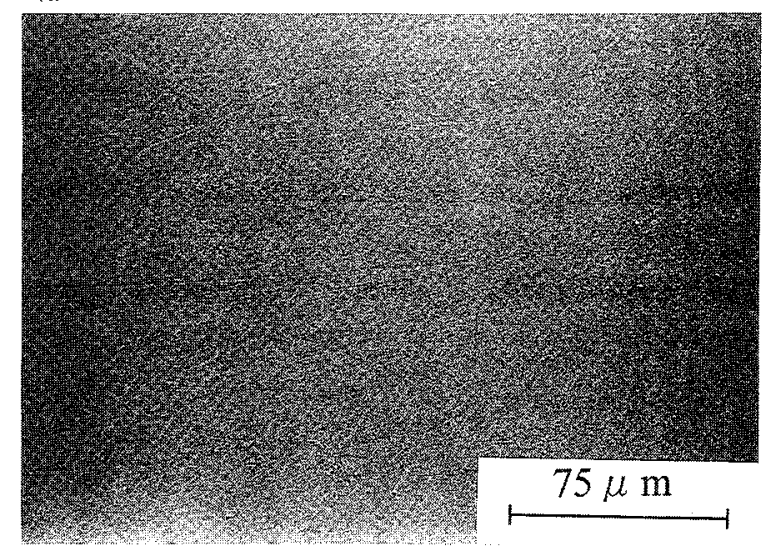

(b)

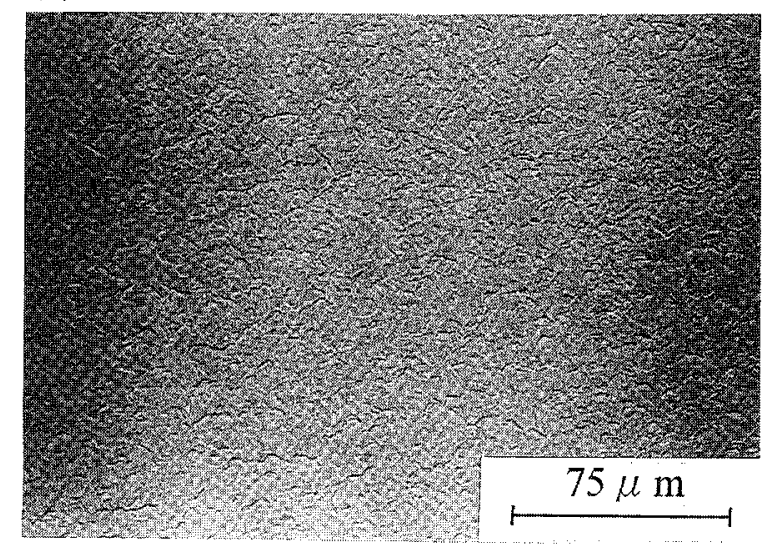

Fig. 7 SEM photographs of $\mathrm{ZnSe}$ films grown at $T_{\text {growth }}=723$ $\mathrm{K}$ with $f_{\mathrm{NF}_{3}}=$ (a) 0.033 and (b) $0.5 \mu \mathrm{mol} / \mathrm{s}$.

ークが低エネルギー側の $2.690 \mathrm{eV} て ゙$ 観測された。

このよらな D-A 対発光の存在と $\mathrm{NF}_{3}$ 添加量の増加に伴ら D-A 発光ピークの低エネルギー側への移動は, $\mathrm{N}$ 添加に伴 うドナーレベルの変化に伴う現象に対応し(14), $\mathrm{NF}_{3}$ 添加に よる $\mathrm{N}$ 添加を示唆するものである.今後さらに伝尊型やキ ヤリア濃度に刘与る評価を行ら必要がある。

\section{4. 表面形態}

無添加の場合には，表面形態は全ガス流束に依存すること が知られ，その制御により鏡面に近い表面が得られることが 知られた，一力， $\mathrm{NF}_{3}$ 添加の場合に性，平坦な表面は得ら れなかった。特に成長速度が急激に増大する $f_{\mathrm{NF}_{3}}>3.0 \times$ $10^{-7} \mathrm{~mol} / \mathrm{s} の$ 領域では大さな表面の起伏が観測された。 Fig. 7 は $\mathrm{NF}_{3}$ 添加量に低存する表面 SEM 写真を示す.

\section{N. 結言}

常压 MOCVD 法により GaAs (100) 基板上に $\mathrm{ZnSe}$ 薄膜を エピタキシャル成長させた。

(1) 無添加の場合について，成長温度拈よ゙゙ $[\mathrm{V}] /[\mathrm{II}]$ 比 
と成長速度との関俰を求め，従来の報告に対応する結果を得 た。

(2) $\mathrm{NF}_{3}$ 添加に扣いて, $f_{\mathrm{NF}_{3}}<3.0 \times 10^{-7} \mathrm{~mol} / \mathrm{s}$ に扣いて は成長速度の増大はわずかであった。この領域に打いて得ら れた薄膜の PL スペクトルに打いて，D-A 対発光が支配的で あった。この D-A 対発光の存在は，これまで報告された窒 素添加 $\mathrm{ZnSe}$ に対するスペクトルに対応することから， $\mathrm{NF}_{3}$ 添加による $\mathrm{N}$ 添加を示唆する。

(3) $f_{\mathrm{NF}_{3}}>3.0 \times 10^{-7} \mathrm{~mol} / \mathrm{s}$ に和いては，成長速度が急激 に増大し，無添加の場合の約 5 倍に達した。この急激な立 上りは $[\mathrm{V}] /[\mathrm{II}]$ 比などの成長条件に依存与る可能性がある.

この領域に颃いて得られた薄膜の PL スペクトルでは，深 い準位のピークが支配的となった。

（4）成長速度の増加に伴い，表面の形態が劣化する傾向が 見られた。 $\mathrm{NF}_{3}$ を添加した試料はとの傾向が特に大きかっ た。

(5) 今後の課題として, $\mathrm{NF}_{3}$ 添加に扣いて $f_{\mathrm{NF}_{3}}$ 值のさら 飞詳細な制御や，減圧系での MOCVDによって表面の改善 を試みる必要がある。成長温度が $\mathrm{MBE}$ 法に比べて高温であ ることから GaAs 基板からの拡散による深い準位の発生に伴 らキャリアの補償の可能性があるので，ホモエピタキシャル 成長の研究が必要である。

本研究を進めるに当たり東北大学工学部の須藤 建教授に 有益な議論を賜りました. Dektak3030の使用に際しては財 団法人半導体研究所の把世話になりました，PL 測定では同
大学工学部の奥貫雄一郎氏に，膜厚测定では長井基将氏にご 支援を頂きましたＳSEM 観察では久保田二郎氏に沶世話に なりました，以上記して謝意を表します。

\section{文献}

(1) M. A. Haase, J. Qiu, J. M. DePuydt and H. Cheng: Appl. Phys. Lett., 59(1991), 1272.

(2) N. Nakayama, S. Itoh, T. Ohta, K. Nakano, H. Okuyama, M. Ozawa, A. Ishibashi, M. Ikeda and Y. Mori: Electron. Lett., 29 (1993), 1488.

(3) S. Itoh, N. Nakayama, S. Matsumoto, M. Nagai, K. Nakano, M. Ozawa, H. Okuyama, S. Tomiya, T. Ohata, M. Ikeda, A. Ishibashi and Y. Mori: Jpn. J. Appl. Phys., 33 (Pt.2) (1994), L938.

（4）石橋 晃: 応用物理，63(1994)，596

(5) M. A. Ruetter and J. M. Vohs: J. Cryst. Growth, 131(1993), 49.

(6) H. Manasevit and W. I. Simpson: J. Electrochem. Soc., $118(1971), 644$.

(7) S. H. Li, C. H. Chen, D. H. Jaw and G. B. Stringfellow: Appl. Phys. Lett., 59(1991), 2124.

(8) M. Mikami, K.-S. Park, Y. Noda and Y. Furukawa: J. Cryst. Growth, 140(1994), 429.

(9) H. Mitsuhashi, I. Mitsuhashi and H. Kukimoto: J. Cryst. Growth, 77(1986), 219.

(10) S. Fujita, H. Mimoto and T. Noguchi: J. Appl. Phys., 50(1979), 1079.

(11) M. Isshiki, T. Yoshida, K. Igaki, W. Uchida and S. Sato: J. Cryst. Growth, 72(1985), 162.

(12) J. L. Merz, K. Nassau and J. W. Shiever: Phys. Rev., B8 (1973), 1444.

(13) P. J. Dean: Phys. Stat. Sol., (a) 81(1984), 625.

(14) J. Qiu, J. M. DePuydt, H. Cheng and M. A. Haase: Appl. Phys. Lett., $\mathbf{5 9}$ (1991), 2992. 